\title{
Antioxidant activities of the extracts from chestnut flower, leaf, skins and fruit
}

\author{
João C.M. Barreira ${ }^{a, b}$, Isabel C.F.R. Ferreira ${ }^{a, *}$, M. Beatriz P.P. Oliveira ${ }^{b}$, \\ José Alberto Pereira ${ }^{\mathrm{a}}$ \\ ${ }^{a}$ CIMO/Escola Superior Agrária, Instituto Politécnico de Bragança, Campus de Santa Apolónia, Apartado 1172, 5301-855 Bragança, Portugal \\ ${ }^{\mathrm{b}}$ REQUIMTE/Serviço de Bromatologia, Faculdade de Farmácia da Universidade do Porto, Rua Aníbal Cunha, 164, 4099-030 Porto, Portugal
}

Received 22 May 2007; received in revised form 17 August 2007; accepted 11 September 2007

\begin{abstract}
In this study, the antioxidant properties of chestnut (flowers, leaves, skins and fruits) extracts were evaluated through several biochemical assays: DPPH (2,2-diphenyl-1-picrylhydrazyl) radical-scavenging activity, reducing power, inhibition of $\beta$-carotene bleaching, inhibition of oxidative hemolysis in erythrocytes, induced by $2,2^{\prime}$-azobis(2-amidinopropane)dihydrochloride (AAPH), and inhibition of lipid peroxidation in pig brain tissue through the formation of thiobarbituric acid-reactive substances (TBARS). These assays have been extensively studied as models for the peroxidative damage in biomembranes. The $\mathrm{EC}_{50}$ values were calculated for all the methods in order to evaluate the antioxidant efficiency of each chestnut extract. The phenol and flavonoid contents were also obtained. Chestnut skins revealed the best antioxidant properties, presenting much lower $\mathrm{EC}_{50}$ values, particularly for lipid peroxidation inhibition in the TBARS assay. Furthermore, the highest antioxidant contents (polyphenols and flavonoids) were found for these extracts.
\end{abstract}

(C) 2007 Published by Elsevier Ltd.

Keywords: Chestnut extracts; Antioxidants; Scavenging effects; Peroxidation and hemolysis inhibition

\section{Introduction}

Free radicals were a major interest for early physicists and radiologists and much later found to be a product of normal metabolism. Today, we know well that radicals cause molecular transformations and gene mutations in many types of organisms. Although oxygen is essential for aerobic forms of life, oxygen metabolites are highly toxic. In healthy individuals, free radical production is continuously balanced by natural antioxidative defence systems (Gutteridge, 1993; Knight, 1995). Disruption of the balance between reactive oxygen species (ROS) production and elimination, due, among other things, to aging, leads to the process called oxidative stress. As a consequence, ROS are known to be implicated in many cell disorders and in the development of many diseases including cardio-

\footnotetext{
* Corresponding author. Tel.: +351 273 303219; fax: +351 273325405.

E-mail address: iferreira@ipb.pt (I.C.F.R. Ferreira).
}

vascular diseases, atherosclerosis, cataracts, chronic inflammation, and neurodegenerative diseases, such as Alzheimer's or Parkinson's disease (Gutteridge, 1993; Knight, 1995). ROS and free radicals are also considered as inducers of lipid peroxidation and cause the deterioration of foods (Rechner et al., 2002). Although organisms have endogenous antioxidant defences produced during normal cell aerobic respiration against ROS, other antioxidants are taken from the diet, both from natural and synthetic origin (Rechner et al., 2002). Antioxidants, which can inhibit or delay the oxidation of an oxidizable substrate in a chain reaction, therefore, appear to be very important in the prevention of many diseases (Halliwell, Gutteridge, \& Cross, 1992). Thus, synthetic antioxidants are widely used in the food industry. However, because of their toxic and carcinogenic effects, their use is being restricted. Thereby, interest in finding natural antioxidants, without undesirable side effects, has increased greatly (Rechner et al., 2002). 
The number of antioxidant compounds synthesized by plants as secondary products, mainly phenolics, serving in plant defence mechanisms to counteract ROS in order to survive, is currently estimated to be between 4000 and 6000 (Havsteen, 2002; Robards, Prenzler, Tucker, Swatsitang, \& Glover, 1999; Wollgast \& Anklam, 2000). The antioxidant activities of phenolics are related to a number of different mechanisms, such as free radical-scavenging, hydrogen-donation, singlet oxygen quenching, metal ion chelation, and acting as a substrate for radicals such as superoxide and hydroxyl. A direct relationship has been found between the content of total phenolics and antioxidant capacity of plants (Ferreira, Baptista, Vilas-Boas, \& Barros, 2007; Robards et al., 1999). In fact, to counteract deleterious action of ROS, phenolic compounds, naturally distributed in plants, are effective (Ferreira, Barros, Soares, Bastos, \& Pereira, 2007; Pereira et al., 2006).

Polyphenols are bioactive compounds believed to be involved in the defence process against deleterious oxidative damage, at least in part, due to their antioxidant properties (Fresco, Borges, Diniz, \& Marques, 2006). Phenolic acids have been widely investigated as potential models for the development of new primary antioxidants, which can prevent or delay in vitro and/or in vivo oxidation processes (Siquet, Paiva Martins, Lima, Reis, \& Borges, 2006). These phenolic compounds are powerful antioxidants and act in a structure-dependent manner, since they can scavenge reactive oxygen species (ROS), and chelate transition metals which play vital roles in the initiation of deleterious free radical reactions (Fresco et al., 2006).

Because purified phenolic compounds are difficult to obtain and because extracts sometimes have better antioxidant activities than those of pure molecules, there is a growing interest for the use of plant extracts (Calliste, Trouillas, Allais, \& Duroux, 2005). Efforts have been made to search for selective and efficient antineoplasic agents to control tumor cell growth. Recent studies have shown that increased consumption of vegetables and fruits is associated with a decreased risk of cancer. Natural antioxidant phenolic acids, and their derivatives, either present in the diet or synthetically prepared, were shown to have promising chemopreventive properties, being identified as promising agents for future development (Fang, Yang, \& Wu, 2002).

To find new natural sources of active compounds, we studied the antioxidant potential of different extracts of Castanea sativa Miller. Among the 12 world chestnut species, this one is the most consumed, being predominant in Portugal, with a relevant place at the socioeconomic level, reaching an annual fruit production of 20,000 tons. The best development conditions are found at altitudes above $500 \mathrm{~m}$ and winter low temperatures, as in the Bragança region (Northeast of Portugal) in which 12,500 ha are used for chestnut cultivation (Ribeiro et al., 2007).

Although it has already been demonstrated that chestnut fruits (Ribeiro et al., 2007) and leaves (Calliste et al., 2005) contain phenolic compounds, little is known about their antioxidant potential or about other chestnut extracts, such as skins and flowers. Accordingly, in this work, the antioxidant properties of chestnut extracts were evaluated through several biochemical assays: DPPH (2,2-diphenyl-1-picrylhydrazyl) radical-scavenging activity, reducing power, inhibition of $\beta$-carotene bleaching, inhibition of oxidative hemolysis in erythrocytes, induced by 2,2'azobis(2-amidinopropane)dihydrochloride (AAPH), and inhibition of lipid peroxidation in pig brain tissue through the formation of thiobarbituric acid-reactive substances (TBARS).

\section{Materials and methods}

\subsection{Standards and reagents}

Standards; BHA (2-tert-butyl-4-methoxyphenol), TBHQ (tert-butylhydroquinone), L-ascorbic acid, $\alpha$-tocopherol, gallic acid and $(+)$-catechin, were purchased from Sigma (St. Louis, MO, USA). 2,2-diphenyl-1-picrylhydrazyl (DPPH ${ }^{-}$) was obtained from Alfa Aesar (Ward Hill, MA, USA). All other chemicals were obtained from Sigma Chemical Co. (St. Louis, MO, USA). Methanol was obtained from Pronalab (Lisbon, Portugal). Water was treated in a Mili-Q water purification system (TGI Pure Water Systems, USA).

\subsection{Samples and sample preparation}

Samples were obtained from the Cv. Longal variety in a orchard located in Vinhais (Trás-os-Montes), in the Northeast side of Portugal. The samples of flowers and fruits of chestnut tree were collected on July 12th, and the fruits were collected on November 12th, according to the tree phonological cycle.

Samples (chestnut fruit, chestnut leaves and chestnut flowers) were kept at $-20{ }^{\circ} \mathrm{C}$ and protected from light prior to further use. For antioxidant compounds extraction, a fine dried powder (20 mesh) of sample (chestnut fruit, chestnut inner skin, chestnut outer skin, chestnut flower and chestnut leaves, $5 \mathrm{~g}$ for all extracts) was extracted using $50 \mathrm{ml}$ of water at boiling temperature for $30 \mathrm{~min}$. The extracts were filtered through Whatman No. 4 paper under reduced pressure, frozen and then lyophilized (Ly-8-FMULE, Snijders). All the samples were redissolved in water at a concentration of $20 \mathrm{mg} / \mathrm{ml}$ and analysed for their contents of polyphenols and flavonoids, and DPPH radical-scavenging activity, reducing power, inhibition of erythrocyte hemolysis, inhibition of $\beta$-carotene bleaching and inhibition of lipid peroxidation.

\subsection{Determination of antioxidant contents}

Contents of total phenolics in the extracts were estimated by a colorimetric assay based on procedures described by Singleton and Rossi (1965) with some modifications. Basically, $1 \mathrm{ml}$ of sample was mixed with $1 \mathrm{ml}$ of 
Folin and Ciocalteu's phenol reagent. After $3 \mathrm{~min}, 1 \mathrm{ml}$ of saturated sodium carbonate solution was added to the mixture and it was adjusted to $10 \mathrm{ml}$ with distilled water. The reaction was kept in the dark for 90 min, after which the absorbance was read at $725 \mathrm{~nm}$ (Analytik Jena 200-2004 spectrophotometer). Gallic acid was used for constructing the standard curve $(0.01-0.4 \mathrm{mM} ; \quad y=2.94848 \times$ $\left.-0.09211 ; R^{2}=0.99914\right)$ and the results were expressed as $\mathrm{mg}$ of gallic acid equivalents/g of extract (GAEs).

Flavonoid contents in the extracts were determined by a colorimetric method described by Jia, Tang, and Wu (1999) with some modifications. The chestnut extract $(250 \mu \mathrm{l})$ was mixed with $1.25 \mathrm{ml}$ of distilled water and $75 \mu 1$ of a $5 \%$ $\mathrm{NaNO}_{2}$ solution. After $5 \mathrm{~min}, 150 \mu \mathrm{l}$ of $10 \% \mathrm{AlCl}_{3} \cdot \mathrm{H}_{2} \mathrm{O}$ solution was added. After $6 \mathrm{~min}, 500 \mu \mathrm{l}$ of $1 \mathrm{M} \mathrm{NaOH}$ and $275 \mu \mathrm{l}$ of distilled water were added to prepare the mixture. The solution was mixed well and the absorbance was read at $510 \mathrm{~nm}$. (+)-Catechin was used to calculate the standard curve $\left(0.250-2.500 \mathrm{mM} ; \quad Y=0.2903 ; \quad R^{2}=\right.$ $1.0000)$ and the results were expressed as $\mathrm{mg}$ of $(+)$-catechin equivalents (CEs) per $\mathrm{g}$ of extract.

\subsection{DPPH radical-scavenging activity}

Various concentrations of chestnut extracts $(0.3 \mathrm{ml})$ were mixed with $2.7 \mathrm{ml}$ of methanolic solution containing DPPH radicals $\left(6 \times 10^{-5} \mathrm{~mol} / \mathrm{l}\right)$. The mixture was shaken vigorously and left to stand for $60 \mathrm{~min}$ in the dark (until stable absorbance values were obtained). The reduction of the DPPH radical was determined by reading the absorbance at $517 \mathrm{~nm}$. The radical-scavenging activity (RSA) was calculated as a percentage of DPPH discoloration, using the equation: \% RSA $=\left[\left(A_{\mathrm{DPPH}}-A_{\mathrm{S}}\right) / A_{\mathrm{DPPH}}\right] \times 100$, where $A_{\mathrm{S}}$ is the absorbance of the solution when the sample extract is added at a particular level, and $A_{\mathrm{DPPH}}$ is the absorbance of the $\mathrm{DPPH}^{\cdot}$ solution (Barros, Baptista, \& Ferreira, $2007)$. The extract concentration providing $50 \%$ of radical-scavenging activity $\left(\mathrm{EC}_{50}\right)$ was calculated from the graph of RSA percentage against extract concentration. BHA and $\alpha$-tocopherol were used as standards.

\subsection{Reducing power}

Various concentrations of chestnut extracts $(2.5 \mathrm{ml})$ were mixed with $2.5 \mathrm{ml}$ of $200 \mathrm{mM}$ sodium phosphate buffer ( $\mathrm{pH} 6.6$ ) and $2.5 \mathrm{ml}$ of $1 \%$ potassium ferricyanide. The mixture was incubated at $50{ }^{\circ} \mathrm{C}$ for $20 \mathrm{~min}$. After $2.5 \mathrm{ml}$ of $10 \%$ trichloroacetic acid ( $\mathrm{w} / \mathrm{v})$ was added, the mixture was centrifuged at $1000 \mathrm{rpm}$ for $8 \mathrm{~min}$ (Centorion K24OR-2003 refrigerated centrifuge). The upper layer $(5 \mathrm{ml})$ was mixed with $5 \mathrm{ml}$ of deionised water and $1 \mathrm{ml}$ of $0.1 \%$ of ferric chloride, and the absorbance was measured spectrophotometrically at $700 \mathrm{~nm}$ (Barros et al., 2007). The extract concentration providing 0.5 of absorbance $\left(\mathrm{EC}_{50}\right)$ was calculated from the graph of absorbance at $700 \mathrm{~nm}$ against extract concentration. BHA and $\alpha$-tocopherol were used as standards.

\subsection{Inhibition of $\beta$-carotene bleaching}

The antioxidant activity of chestnut extracts was evaluated by the $\beta$-carotene linoleate model system. A solution of $\beta$-carotene was prepared by dissolving $2 \mathrm{mg}$ of $\beta$-carotene in $10 \mathrm{ml}$ of chloroform. Two millilitres of this solution was pipetted into a $100 \mathrm{ml}$ round-bottom flask. After the chloroform was removed at $40{ }^{\circ} \mathrm{C}$ under vacuum, $40 \mathrm{mg}$ of linoleic acid, $400 \mathrm{mg}$ of Tween 80 emulsifier, and $100 \mathrm{ml}$ of distilled water were added to the flask with vigorous shaking. Aliquots $(4.8 \mathrm{ml})$ of this emulsion were transferred into different test tubes containing $0.2 \mathrm{ml}$ of different concentrations of the chestnut extracts. The tubes were shaken and incubated at $50{ }^{\circ} \mathrm{C}$ in a water bath. As soon as the emulsion was added to each tube, the zero time absorbance was measured at $470 \mathrm{~nm}$ using a spectrophotometer. Absorbance readings were then recorded at 20 min intervals until the control sample had changed colour. A blank, devoid of $\beta$-carotene, was prepared for background subtraction. Lipid peroxidation (LPO) inhibition was calculated using the following equation: LPO inhibition $=(\beta$-carotene content after $2 \mathrm{~h}$ of assay/initial $\beta$-carotene content $) \times 100$ (Barros et al., 2007). The extract concentration providing $50 \%$ antioxidant activity $\left(\mathrm{EC}_{50}\right)$ was calculated from the graph of antioxidant activity percentage against extract concentration. TBHQ was used as standard.

\subsection{Inhibition of erythrocyte hemolysis mediated by peroxyl free radicals}

The antioxidant activity of the chestnut extracts was measured as the inhibition of erythrocyte hemolysis. Blood was obtained from a male ram (churra galega transmontana) of body weight $\sim 67 \mathrm{~kg}$. Erythrocytes separated from the plasma and the buffy coat were washed three times with $10 \mathrm{ml}$ of $10 \mathrm{mM}$ phosphate buffer saline (PBS) at $\mathrm{pH} 7.4$ (prepared by mixing $10 \mathrm{mM}$ of $\mathrm{NaH}_{2} \mathrm{PO}_{4}$ and $\mathrm{Na}_{2} \mathrm{HPO}_{4}$, and $125 \mathrm{mM}$ of $\mathrm{NaCl}$ in 11 of distilled water) and centrifuged at $1500 \mathrm{~g}$ for $5 \mathrm{~min}$. During the last washing, the erythrocytes were obtained by centrifugation at $1500 \mathrm{~g}$ for $10 \mathrm{~min} .0 .1 \mathrm{ml}$ of a $20 \%$ suspension of erythrocytes in PBS was added to

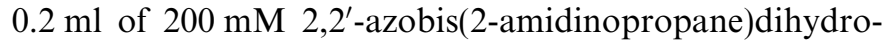
chloride (AAPH) solution (in PBS) and $0.1 \mathrm{ml}$ of chestnut methanolic extracts of different concentrations. The reaction mixture was shaken gently $(30 \mathrm{rpm})$ while being incubated at $37^{\circ} \mathrm{C}$ for $3 \mathrm{~h}$. The reaction mixture was diluted with $8 \mathrm{ml}$ of PBS and centrifuged at $3000 \mathrm{~g}$ for $10 \mathrm{~min}$; the absorbance of its supernatant was then read at $540 \mathrm{~nm}$ by a spectrophotometer, after filtration with a syringe filter (cellulose membrane $30 \mathrm{~mm}, 0.20 \mu \mathrm{m}$, Titan). The percentage hemolysis inhibition was calculated by the equation $\%$ hemolysis inhibition $=\left[\left(A_{\mathrm{AAPH}}-A_{\mathrm{S}}\right) / \mathrm{A}_{\mathrm{AAPH}}\right] \times 100$, where $A_{\mathrm{S}}$ is the absorbance of the sample containing the chestnut extract, and $A_{\mathrm{AAPH}}$ is the absorbance of the control sample containing no chestnut extract (Barros et al., 2007). The extract concentration providing $50 \%$ inhibition $\left(\mathrm{EC}_{50}\right)$ was calculated 
from the graph of hemolysis inhibition percentage against extract concentration. L-Ascorbic acid was used as standard.

\subsection{Inhibition of lipid peroxidation using thiobarbituric acid- reactive substances (TBARS)}

Brains were obtained from pig (Sus scrofa) of body weight $\sim 150 \mathrm{~kg}$, dissected and homogenized with a Polytron in ice-cold Tris- $\mathrm{HCl}$ buffer $(20 \mathrm{mM}, \mathrm{pH} 7.4)$ to produce a 1:2(w/v) brain tissue homogenate which was centrifuged at $3000 \mathrm{~g}$ for $10 \mathrm{~min}$. An aliquot $(0.1 \mathrm{ml})$ of the supernatant was incubated with the chestnut extracts $(0.2 \mathrm{ml})$ in the presence of $\mathrm{FeSO}_{4}(10 \mu \mathrm{M} ; 0.1 \mathrm{ml})$ and ascorbic acid $(0.1 \mathrm{mM} ; 0.1 \mathrm{ml})$ at $37^{\circ} \mathrm{C}$ for $1 \mathrm{~h}$. The reaction was stopped by the addition of trichloroacetic acid $(28 \% \mathrm{w} / \mathrm{v}, 0.5 \mathrm{ml})$, followed by thiobarbituric acid (TBA, $2 \%, \mathrm{w} / \mathrm{v}, 0.38 \mathrm{ml}$ ), and the mixture was then heated at $80^{\circ} \mathrm{C}$ for $20 \mathrm{~min}$. After centrifugation at $3000 \mathrm{~g}$ for $10 \mathrm{~min}$ to remove the precipitated protein, the colour intensity of TBARS in the supernatant was measured by its absorbance at $532 \mathrm{~nm}$. The inhibition ratio (\%) was calculated using the following formula: Inhibition ratio $(\%)=[(A-B) / A] \times 100 \%$, where $A$ and $B$ are the absorbances of the control and the extract solution, respectively. The extract concentration providing 50\% lipid peroxidation inhibition $\left(\mathrm{EC}_{50}\right)$ was calculated from the graph of antioxidant activity percentage against extract concentration. BHA was used as standard.

\subsection{Statistical analysis}

For all the experiments three samples were analysed and all the assays were carried out in triplicate. The results are expressed as mean values and standard error or standard deviation (SD). The differences between the chestnut extracts were analysed using one-way analysis of variance (ANOVA), followed by Tukey's HSD Test with $\alpha=0.05$. This treatment was carried out using the SAS v. 9.1.3 programme. The regression analysis between phenol or flavonoid contents and $\mathrm{EC}_{50}$ values for antioxidant activity used the same statistical package.

\section{Results and discussion}

Table 1 presents extraction yields (expressed as w/w percentages), polyphenols and flavonoid contents, obtained for all the chestnut extracts. Among all of the extracts analysed, a significant content of total phenolics $(>100 \mathrm{mg} / \mathrm{g}$ of extract, this is more than $10 \%$, for each chestnut compound) and good radical-scavenging activity were found for all extracts, except for fruit. It became clear that chestnut leaves, skins and flower present the highest antioxidant activity (Table 1). Despite the low values obtained for the extraction yields, the antioxidant contents found were very good, indicating that the extraction was efficient. Nevertheless, a relationship between the extracted mass and the corresponding polyphenols and flavonoids was not observed in all cases. Probably, fruits and leaves contain higher amounts of other polar compounds in addition to the antioxidants quantified in this study when compared with chestnut flowers and skins. It is well-known that the skins of the chestnut are rich in tannin (Hwang, Hwang, \& Park, 2001); these phenolic compounds might account for the values obtained while, in other extracts, such as chestnut fruit, the content of total phenolics in the extracted mass is, most likely, quite low. Otherwise, we should have obtained much higher values, bearing in mind that the tannin of chestnut fruit is mainly gallic acid, consisting of 3,6digalloylglucose, pyrogallol, and resorcinol (Hwang et al., 2001).

Polyphenols and flavonoids were found in all the samples and in the following order: outer skins > inner skins $>$ flowers $>$ leaves $\ggg$ fruit. The coefficients of variation $(\mathrm{CV}$; calculated by the ratio between standard deviation and mean) are also presented. CV values revealed high reproducibility, ranging from $1.92 \%$ (flower) to $5.70 \%$ (inner skin) for polyphenol contents, and from 1.86\% (inner skin) to $6.97 \%$ (fruit) for flavonoid contents.

Figs. 1-5 show the antioxidant activity of chestnut extracts examined as a function of their concentration. Several biochemical assays were used to screen the antioxidant properties: scavenging activity on DPPH radicals (measuring the decrease in DPPH radical absorption after exposure to radical scavengers), reducing power (measuring the conversion of a $\mathrm{Fe}^{3+}$ /ferricyanide complex to the ferrous form), inhibition of $\beta$-carotene bleaching (by neutralizing the linoleate-free radical and other free radicals formed in the system which attack the highly unsaturated $\beta$-carotene models), hemolysis inhibition (evaluating the protective effect of the extracts on hemolysis by peroxyl radical-scavenging activity) and inhibition of lipid peroxidation in brain tissue (measured by the colour intensity of MDA-TBA

Table 1

Extraction yields, and contents of total phenolics and flavonoids in the extracts of chestnuts, and corresponding coefficients of variation

\begin{tabular}{|c|c|c|c|c|c|c|}
\hline & & Flower & Leaf & Outer skin & Inner skin & Fruit \\
\hline Extraction yield & $(\%)$ & $16.3 \pm 0.95 b$ & $20.9 \pm 1.22 \mathrm{a}$ & $4.98 \pm 0.19 \mathrm{c}$ & $21.6 \pm 2.38 \mathrm{a}$ & $19.6 \pm 0.87 \mathrm{ab}$ \\
\hline Polyphenols & $\begin{array}{l}(\mathrm{mg} / \mathrm{g}) \\
\mathrm{CV}(\%)\end{array}$ & $\begin{array}{l}298 \pm 5.73 \mathrm{c} \\
1.92\end{array}$ & $\begin{array}{l}103 \pm 2.98 \mathrm{~d} \\
2.90\end{array}$ & $\begin{array}{l}510 \pm 18.70 \mathrm{a} \\
3.69\end{array}$ & $\begin{array}{l}475 \pm 27.04 \mathrm{~b} \\
5.70\end{array}$ & $\begin{array}{l}3.73 \pm 0.11 \mathrm{e} \\
2.84\end{array}$ \\
\hline Flavonoids & $\begin{array}{l}(\mathrm{mg} / \mathrm{g}) \\
\mathrm{CV}(\%)\end{array}$ & $\begin{array}{l}160 \pm 5.32 \mathrm{c} \\
3.33\end{array}$ & $\begin{array}{l}54.5 \pm 3.74 \mathrm{~d} \\
6.86\end{array}$ & $\begin{array}{l}503 \pm 11.21 \mathrm{a} \\
2.23\end{array}$ & $\begin{array}{l}330 \pm 6.13 b \\
1.86\end{array}$ & $\begin{array}{l}2.30 \pm 0.16 \mathrm{e} \\
6.97\end{array}$ \\
\hline
\end{tabular}

In each line, different letters mean significant differences $(p<0.05)$. 


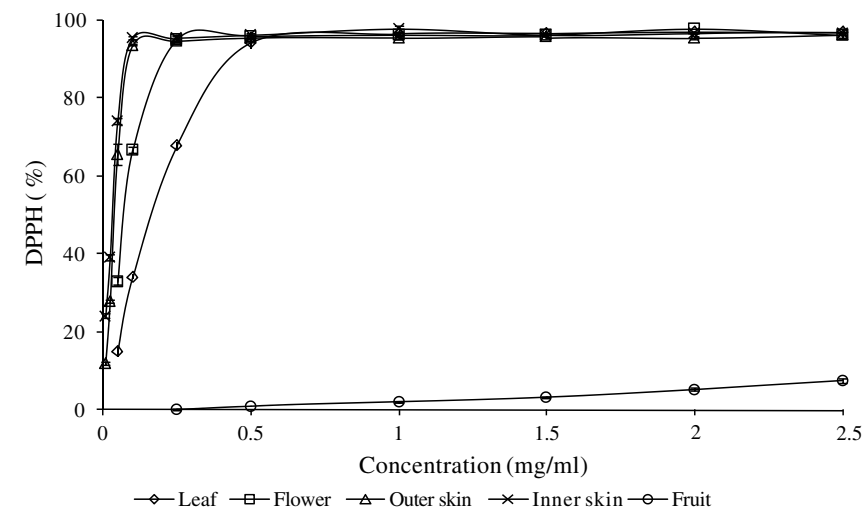

Fig. 1. Radical-scavenging activity (RSA) as a function of chestnut extracts concentration.

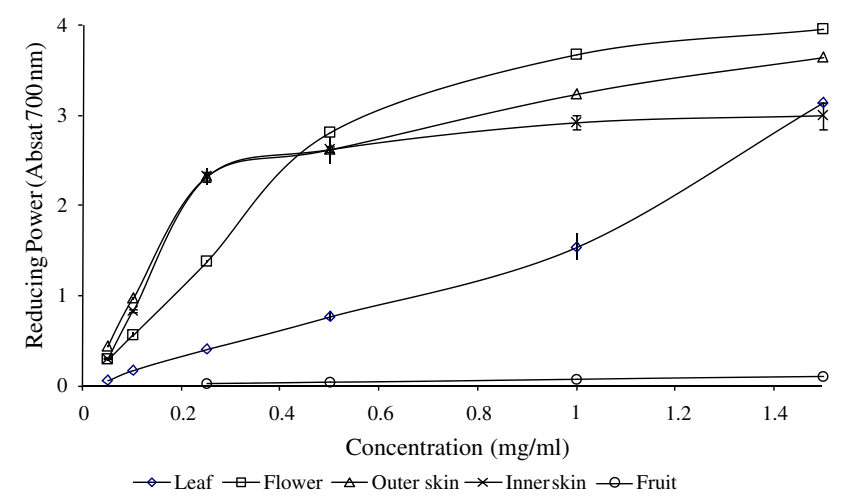

Fig. 2. Reducing power as a function of chestnut extracts concentration.

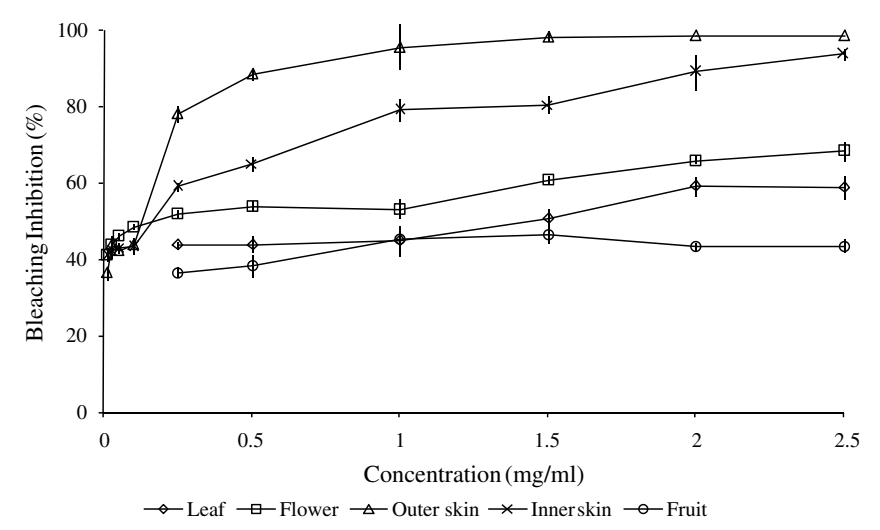

Fig. 3. Inhibition of $\beta$-carotene bleaching as a function of chestnut extracts concentration.

complex). The assays were performed for each extract separately. Nevertheless, those assays were carried out using whole extracts instead of individual compounds. According to Liu (2003), additive and synergistic effects of phytochemicals in fruits and vegetables are responsible for their potent bioactive properties and the benefit of a diet rich in fruits and vegetables is attributed to the complex mixture of phytochemicals present in whole foods. This explains why no

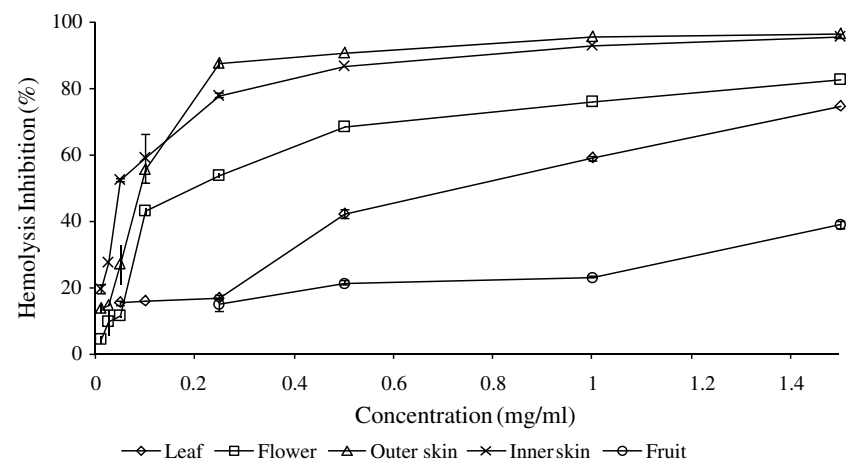

Fig. 4. Hemolysis inhibition as a function of chestnut extracts concentration.

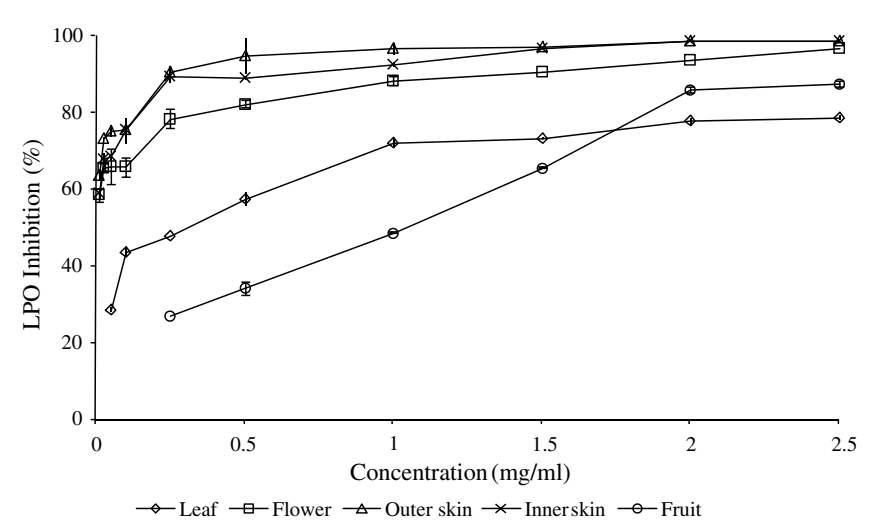

Fig. 5. Lipid peroxidation (LPO) inhibition as a function of chestnut extracts concentration.

single antioxidant can replace the combination of natural phytochemicals to achieve the health benefits. Analysis of Figs. 1-5 revealed that antioxidant activity increased with the concentration, very good results being obtained, even at low extract concentrations.

For better understanding, the results are not fully shown; some of the concentrations (mainly in the case of chestnut fruit higher concentrations) have been removed. The radical-scavenging activity (RSA) values were expressed as the ratio percentage of sample absorbance decrease and the absorbance of $\mathrm{DPPH}^{-}$solution in the absence of extract at $517 \mathrm{~nm}$. From the analysis of Fig. 1, we can conclude that the scavenging effects of all extracts on DPPH radicals increased with the concentration increase and were excellent, especially in the case of chestnut skins $(93.8 \%$ at $0.1 \mathrm{mg} / \mathrm{ml}$ for the outer skin and $95.6 \%$ for the inner skin, at the same concentration). The RSA values were also remarkably good for flowers $(95.3 \%$ at $0.25 \mathrm{mg} / \mathrm{ml}$ ) and leaves $(94.4 \%$ at $0.5 \mathrm{mg} / \mathrm{ml})$, but chestnut fruit revealed a very low value $(27.8 \%$ at $10 \mathrm{mg} / \mathrm{ml})$.

The reducing power also increased with concentration, and the values obtained for all the extracts were excellent (Fig. 2). At $1 \mathrm{mg} / \mathrm{ml}$, the absorbance values were above 1.5 for all extracts, once more with the exception of chestnut fruit. The extracts obtained with flowers and skins 
showed similar values, while leaf showed less good results. It has been reported that the reducing properties are generally associated with the presence of reductones, which have been shown to exert antioxidant action by breaking the free radical chain by donating a hydrogen atom (Shimada, Fujikawa, Yahara, \& Nakamura, 1992). Hence, flower and skin may have high amounts of reductones. Chestnut fruit, as has already been pointed out, presented the worst result, with a value of 0.55 in absorbance obtained at just $10 \mathrm{mg} / \mathrm{ml}$, a very high concentration value, when compared with the other extracts.

The bleaching inhibition, measured by the peroxidation of $\beta$-carotene, is presented in Fig. 3. The linoleic acid free radical attacks the highly unsaturated $\beta$-carotene. The presence of different antioxidants can hinder the extent of $\beta$-carotene bleaching by neutralizing the linoleate-free radical and other free radicals formed in the system (Jayaprakasha, Singh, \& Sakariah, 2001). Accordingly, the absorbance decreased rapidly in samples without antioxidant whereas, in the presence of an antioxidant, samples retained their colour, and thus absorbance, for a longer time. Bleaching inhibition in the presence of different chestnut extracts increased as long as concentration was high, and the values at $1.5 \mathrm{mg} / \mathrm{ml}$ for each one of the extracts were all above $50 \%$, except in the case of chestnut fruit (flower: $61.0 \%$; leaf: 51.0\%; outer skin: $98.3 \%$; inner skin: $80.4 \%$; fruit: $46.8 \%$ ). It is probable that the antioxidative components in the chestnut extracts can reduce the extent of $\beta$-carotene destruction by neutralizing the linoleate-free radical and other free radicals formed in the system. Once more, chestnut skins revealed high effectiveness of antioxidant activity.

AAPH is a peroxyl radical initiator that generates free radicals by its thermal decomposition and will attack erythrocytes to induce the chain oxidation of lipid and protein, disturbing the membrane organization and eventually leading to hemolysis. The extracts inhibited hemolysis as a result of protection against the oxidative damage of cell membranes of erythrocytes from ram, induced by AAPH, in a concentration-dependent manner (Fig. 4). As has already been observed in previous analysis, chestnut skins showed a high protective effect against erythrocyte hemolysis (outer skin: $95.7 \%$, inner skin: $92.7 \%$; at $1 \mathrm{mg} / \mathrm{ml}$ ) when compared with the other studied components (flower: $75.8 \%$, leaf: $59.0 \%$, fruit: $23.3 \%$; at $1 \mathrm{mg} / \mathrm{ml}$ ).

Inhibition of lipid peroxidation was evaluated using thiobarbituric acid-reactive substances (TBARS). This is a highly sensitive method, the results being fully dependent on efficient centrifugation to remove the precipitated protein. Otherwise this will lead to erroneous absorbance results. As can be easily understood from Fig. 5, the capacity of inhibition of lipid peroxidation is proportional to the extract concentration. This method permitted the achievement of very high inhibition percentages at extremely low concentrations. To verify this observation, we can note the percentages obtained at $0.25 \mathrm{mg} / \mathrm{ml}: 78.2 \%$ (flower), $47.7 \%$ (leaf), $90.6 \%$ (outer skin), $89.2 \%$ (inner skin) and $27.0 \%$ (fruit).

Table 2 shows antioxidant activity with $\mathrm{EC}_{50}$ values of chestnut flowers, leaves, outer and inner skins, and fruits measured by different biochemical assays. Overall, chestnut skins revealed the best antioxidant properties (significantly lower $\mathrm{EC}_{50}$ values; $p<0.05$ ). The $\mathrm{EC}_{50}$ values obtained for these extracts were excellent (less than $165 \mu \mathrm{g} / \mathrm{ml}$ ), particularly for LPO inhibition (less than $12 \mu \mathrm{g} / \mathrm{ml}$ ). Chestnut fruit revealed a very poor antioxidant activity; the percentages obtained in the case of RSA did not allow calculation of the $\mathrm{EC}_{50}$ value.

Chestnut flowers and leaves also revealed very good antioxidant activity, while chestnut fruits presented the highest $\mathrm{EC}_{50}$ values in all the tested methods. The obtained results are in agreement with the phenol and flavonoid contents determined for each sample and shown in Table 1 . The $\mathrm{EC}_{50}$ values obtained for lipid peroxidation inhibition were better than those for reducing power, scavenging effects on DPPH radicals, $\beta$-carotene bleaching inhibition caused by linoleate-free radical and for hemolysis inhibition mediated by peroxyl free radicals. All the parameters assayed, present $\mathrm{CV}$ values that reveal high reproducibility, ranging from $0.80 \%$ to $10.9 \%$. In the case of scavenging effect, reducing power, bleaching inhibition, hemolysis inhibition and LPO inhibition, CV values varied from $0.80 \%$ (flower) to $4.75 \%$ (fruit), $0.99 \%$ (leaf) to $8.35 \%$ (outer skin), $6.94 \%$ (leaf) to $10.9 \%$ (flower), $0.90 \%$ (inner skin) to $5.32 \%$ (leaf) and $1.85 \%$ (outer skin) to $3.86 \%$ (leaf), respectively.

Table 2

$\mathrm{EC}_{50}$ values $(\mu \mathrm{g} / \mathrm{ml})$ obtained in the antioxidant assays for chestnut extracts, and corresponding coefficients of variation $(\%)$

\begin{tabular}{|c|c|c|c|c|c|c|}
\hline & & Flower & Leaf & Outer skin & Inner skin & Fruit \\
\hline RSA & $\begin{array}{l}\mathrm{EC}_{50} \\
\mathrm{CV}\end{array}$ & $\begin{array}{l}74.9 \pm 0.60 \mathrm{c} \\
0.80\end{array}$ & $\begin{array}{l}170 \pm 2.49 \mathrm{~b} \\
1.47\end{array}$ & $\begin{array}{l}39.7 \pm 1.11 \mathrm{~d} \\
2.79\end{array}$ & $\begin{array}{l}32.7 \pm 0.38 \mathrm{e} \\
1.16\end{array}$ & $\begin{array}{l}>10,000 \mathrm{a} \\
4.75\end{array}$ \\
\hline Reducing power & $\begin{array}{l}\mathrm{EC}_{50} \\
\mathrm{CV}\end{array}$ & $\begin{array}{l}87.3 \pm 0.03 \mathrm{c} \\
3.52\end{array}$ & $\begin{array}{l}313 \pm 0.03 \mathrm{~b} \\
0.99\end{array}$ & $\begin{array}{l}55.1 \pm 0.05 \mathrm{e} \\
8.35\end{array}$ & $\begin{array}{l}68.7 \pm 0.01 \mathrm{~d} \\
1.23\end{array}$ & $\begin{array}{l}9044 \pm 148 \mathrm{a} \\
1.64\end{array}$ \\
\hline Bleaching inhibition & $\begin{array}{l}\mathrm{EC}_{50} \\
\mathrm{CV}\end{array}$ & $\begin{array}{l}161 \pm 17.54 \mathrm{c} \\
10.9\end{array}$ & $\begin{array}{l}145 \pm 10.59 b \\
6.94\end{array}$ & $\begin{array}{l}133 \pm 11.0 \mathrm{c} \\
8.26\end{array}$ & $\begin{array}{l}164 \pm 13.8 \mathrm{c} \\
8.46\end{array}$ & $\begin{array}{l}3632 \pm 284 \mathrm{a} \\
7.82\end{array}$ \\
\hline Hemolysis inhibition & $\begin{array}{l}\mathrm{EC}_{50} \\
\mathrm{CV}\end{array}$ & $\begin{array}{l}196 \pm 6.88 b \\
3.51\end{array}$ & $\begin{array}{l}169 \pm 8.99 b \\
5.32\end{array}$ & $\begin{array}{l}91.4 \pm 1.52 \mathrm{c} \\
1.67\end{array}$ & $\begin{array}{l}47.5 \pm 0.43 \mathrm{~d} \\
0.90\end{array}$ & $\begin{array}{l}3486 \pm 71.0 \mathrm{a} \\
2.04\end{array}$ \\
\hline
\end{tabular}

In each line, different letters mean significant differences $(p<0.05)$. 
Table 3

Correlations established between total polyphenols and flavonoids with antioxidant activity $\mathrm{EC}_{50}$ values $(\mathrm{df}=4)$

\begin{tabular}{|c|c|c|c|c|c|c|}
\hline \multirow[t]{2}{*}{ Assay } & \multicolumn{3}{|l|}{ Polyphenols } & \multicolumn{3}{|l|}{ Flavonoids } \\
\hline & Equation, $R^{2}$ & $F$ & $p$ & Equation, $R^{2}$ & $F$ & $p$ \\
\hline RSA & $y=-0.3276 x+192.7347,0.939$ & 30.502 & 0.031 & $y=-0.2675 x+149.2648,0.693$ & 4.523 & 0.167 \\
\hline Reducing power & $y=-0.5984 x+338.3081,0.837$ & 10.300 & 0.085 & $y=-0.4810 x+256.9111,0.600$ & 2.994 & 0.226 \\
\hline Hemolysis inhibition & $y=-0.2825 x+223.8487,0.591$ & 2.892 & 0.231 & $y=-0.2564 x+193.1116,0.540$ & 2.347 & 0.265 \\
\hline LPO inhibition & $y=-0.6997 x+327.2144,0.757$ & 6.218 & 0.130 & $y=-0.5394 x+226.0194,0.939$ & 1.986 & 0.294 \\
\hline
\end{tabular}

Other tree nuts have potential antioxidant activity, namely: wallnuts (Anderson et al., 2001; Fukuda, Ito, \& Yoshida, 2004) and hazelnuts (Alasalvar, Karamaca, Amarowicz, \& Shahidi, 2006; Sivakumar \& Bacchetta, 2005). Nevertheless, those studies were carried out with extracts from the fruits, while reports on leaves antioxidant potential were described by us in previous Works (Oliveira et al., 2007; Pereira et al., 2007), and no studies are known on flowers' and barks' antioxidant properties. The results obtained with chestnut flower, leaf, and skins extracts were excellent compared to the results obtained by us for wallnut and hazel leaves $\left(\mathrm{EC}_{50}\right.$ values $\left.\sim 1 \mathrm{mg} / \mathrm{ml}\right)$.

In previous works (Barros et al., 2007; Sousa, Ferreira, Barros, Bento, \& Pereira, in press), we observed a significantly negative linear correlation between the polyphenol contents and $\mathrm{EC}_{50}$ antioxidant activity values. This negative linear correlation proves that the samples with highest polyphenol contents show lower $\mathrm{EC}_{50}$ values, confirming that phenolics are likely to contribute to the antioxidant activity of the extracts, as has been reported in other species (Velioglu, Mazza, Gao, \& Oomah, 1998). The flavonoid contents were also correlated with $\mathrm{EC}_{50}$ scavenging capacity values, although with less good correlation coefficient values (Barros et al., 2007). However, in the present study, despite the high coefficient of correlation values $\left(R^{2}\right)$ obtained, proving the existence of correlation, the only results that showed statistical significance were those gathered for $\mathrm{EC}_{50}$ radical-scavenging activity and polyphenols, as can be seen in Table 3. A similar result was not observed for flavonoids. For all the other antioxidant activity evaluation methods, respectively, for polyphenols and flavonoids, the regression analysis did not reveal statistical significance, probably due to the low number of assays performed.

As far as we know, this is the first report concerning the antioxidant activity of five different chestnut extracts. The work herein indicates that skins present the highest antioxidant activity values. The results obtained indicate a high potential of application for these chestnut extracts, traditionally considered as disposable byproducts. After adequate treatment they can, for example, be included in foods with remarkable benefits for human or animal health.

\section{Acknowledgements}

The authors are grateful to the Foundation for Science and Technology (Portugal) for financial support to
J.C.M. Barreira (SFRH/BD/29060/2006) and INTERREG IIIA project PIREFI.

\section{References}

Alasalvar, C., Karamaca, M., Amarowicz, R., \& Shahidi, F. (2006). Antioxidant and antiradical activities in extracts of hazelnut kernel (Corylus avellana L.) and hazelnut green leafy cover. Journal of Agricultural and Food Chemistry, 54, 4826-4832.

Anderson, K. J., Teuber, S. S., Gobeille, A., Cremin, P., Waterhouse, A. L., \& Steinberg, F. M. (2001). Walnut polyphenolics inhibit in vitro human plasma and LDL oxidation. The Journal of Nutrition, 131, 2837-2842.

Barros, L., Baptista, P., \& Ferreira, I. C. F. R. (2007). Effect of Lactarius piperatus fruiting body maturity stage on antioxidant activity measured by several biochemical assays. Food and Chemical Toxicology, $45,1731-1737$.

Calliste, C.-A., Trouillas, P., Allais, D.-P., \& Duroux, J.-L. (2005). Castanea sativa Mill. leaves as new sources of natural antioxidant: An electronic spin resonance study. Journal of Agriculture and Food Chemistry, 53, 282-288.

Fang, Y.-Z., Yang, S., \& Wu, G. (2002). Free radicals, antioxidants, and nutrition. Nutrition, 18, 872-879.

Ferreira, I. C. F. R., Baptista, P., Vilas-Boas, M., \& Barros, L. (2007). Free-radical scavenging capacity and reducing power of wild edible mushrooms from northeast Portugal. Food Chemistry, 100, 1511-1516.

Ferreira, I. C. F. R., Barros, L., Soares, M. E., Bastos, M. L., \& Pereira, J. A. (2007). Antioxidant activity and phenolic contents of Olea europaea L. leaves sprayed with different copper formulations. Food Chemistry, 103, 188-195.

Fresco, P., Borges, F., Diniz, C., \& Marques, M. P. M. (2006). New insights on the anticancer properties of dietary polyphenols. Medicinal Research Reviews, 26, 747-766.

Fukuda, T., Ito, H., \& Yoshida, T. (2004). Effect of the walnut polyphenol fraction on oxidative stress in type 2 diabetes mice. BioFactors, 21, 251-253.

Gutteridge, J. M. (1993). Free radicals in disease processes: A compilation of cause and consequence. Free Radical Research, 19, 141-158.

Halliwell, B., Gutteridge, J. M., \& Cross, C. E. (1992). Free radicals, antioxidants, and human disease: where are we now. Journal of Laboratory and Clinical Medicine, 119, 598-620.

Havsteen, B. H. (2002). The biochemistry and medical significance of the flavonoids. Pharmacology and Therapeutics, 96, 67-202.

Hwang, J.-Y., Hwang, I.-K., \& Park, J.-B. (2001). Analysis of physicochemical factors related to the automatic pellicle removal in Korean chestnut (Castanea crenata). Journal of Agriculture and Food Chemistry, 49, 6045-6049.

Jayaprakasha, G. K., Singh, R. P., \& Sakariah, K. K. (2001). Antioxidant activity of grape seed (Vitis vinifera) extracts on peroxidation models in vitro. Food Chemistry, 73, 285-290.

Jia, Z., Tang, M., \& Wu, J. (1999). The determination of flavonoid contents in mulberry and their scavenging effects on superoxide radicals. Food Chemistry, 64, 555-559.

Knight, J. A. (1995). Diseases related to oxygen-derived free radicals. Annals of Clinical and Laboratory Sciences, 25, 111-121. 
Liu, R. H. (2003). Health benefits of fruits and vegetables are from additive and synergistic combination of phytochemicals. American Journal of Clinical Nutrition, 78, 517S-520S.

Oliveira, I., Sousa, A., Valentão, P., Andrade, P. B., Ferreira, I. C. F. R., Ferreres, F., et al. (2007). Hazel (Corylus avellana L.) leaves as source of antimicrobial and antioxidative compounds. Food Chemistry, 105, 1018-1025.

Pereira, J. A., Oliveira, I., Sousa, A., Valentão, P., Andrade, P. B., Ferreira, I. C. F. R., et al. (2007). Walnut (Juglans regia L.) leaves: Phenolic compounds, antibacterial activity and antioxidant potential of different cultivars. Food and Chemical Toxicology, 45, 2287-2295.

Pereira, J. A., Pereira, A. P. G., Ferreira, I. C. F. R., Valentão, P., Andrade, P. B., Seabra, R., et al. (2006). Table olives from Portugal: Phenolic compounds, antioxidant potential and antimicrobial activity. Journal of Agriculture and Food Chemistry, 54, 8425-8431.

Rechner, A. R., Kuhnle, G., Bremner, P., Hubbard, G. P., Moore, K. P., \& Rice-Evans, C. A. (2002). The metabolic fate of dietary polyphenols in humans. Free Radical Biology and Medicine, 33, 220-235.

Ribeiro, B., Rangel, J., Valentão, P., Andrade, P. B., Pereira, J. A., Bolke, H., et al. (2007). Organic acids in two Portuguese chestnut (Castanea sativa Miller) varieties. Food Chemistry, 100, 504-508.

Robards, K., Prenzler, P. D., Tucker, G., Swatsitang, P., \& Glover, W. (1999). Phenolic compounds and their role in oxidative processes in fruits. Food Chemistry, 66, 401-436.
Shimada, K., Fujikawa, K., Yahara, K., \& Nakamura, T. (1992). Antioxidative properties of xanthan on the autoxidation of soybean oil in cyclodextrin emulsion. Journal of Agriculture and Food Chemistry, 40, 945-948.

Singleton, V. L., \& Rossi, J. A. Jr., (1965). Colorimetric of total phenolics with phosphomolybdic-phosphotungstic acid reagents. American Journal of Enology and Viticulture, 16, 144-158.

Siquet, C., Paiva Martins, F., Lima, J. L. F. C., Reis, S., \& Borges, F. (2006). Antioxidant profile of dihydroxy- and trihydroxyphenolicacids: A structure-activity relationship study. Free Radical Research, 40, 433-442.

Sivakumar, G., \& Bacchetta, L. (2005). Determination of natural vitamin E from Italian hazelnut leaves. Chemistry of Natural Compounds, 41, 654-656.

Sousa, A., Ferreira, I. C. F. R., Barros, L., Bento, A. \& Pereira, J. A. (in press). Effect of solvent and extraction temperatures on the antioxidant potential of traditional stoned table olives "alcaparras". LWT-Food Science and Technology.

Velioglu, Y. S., Mazza, G., Gao, L., \& Oomah, B. D. (1998). Antioxidant activity and total phenolics in selected fruits, vegetables, and grain products. Journal of Agriculture and Food Chemistry, 46, 4113-4117.

Wollgast, J., \& Anklam, E. (2000). Review on polyphenols in Theobroma cacao: Changes in composition during the manufacture of chocolate and methodology for identification and quantification. Food Research International, 33, 423-447. 